\title{
PROGRAMA DE AÇÕES AFIRMATIVAS DA UNIVERSIDADE FEDERAL DE SANTA CATARINA: RESULTADOS PRELIMINARES
}

\author{
MARCELO HENRIQUE ROMANO TRAGTENBERG
}

Resumo: O Programa de Ações Afirmativas da UFSC foi aprovado em 2007, começou a ser implantado em 2008, com reavaliação cinco anos após, e compreende preparação do acesso, acesso com reserva de vagas para oriundos de escolas públicas e para negros e vagas suplementares para indígenas, ações de permanência, entre outras medidas. Este trabalho mostra indícios presentes nos primeiros resultados do Programa que questionam idéias do senso comum relacionadas a ações afirmativas tais como: cotas para escola pública englobam diversidade racial, ações afirmativas não atraem o público beneficiário como oriundos de escolas públicas, negros e indígenas; somente negros de escola pública devem ser alvo de ação afirmativa; alunos de ação afirmativa se evadem mais; alunos de ação afirmativa de escola pública têm desempenho pior que os da classificação geral; ações afirmativas não tem consistência jurídica.

Palavras-chave: ação afirmativa, cotas, evasão, acesso, permanência.

1. Introdução: Ações Afirmativas para acesso ao Ensino Superior Brasileiro

O expressivo aumento de vagas no ensino superior brasileiro de 1960 até o presente apresentou distorções de forma geral e em algumas carreiras em particular. $\mathrm{O}$ acesso de negros, de forma geral, e de pessoas de baixa renda a algumas carreiras mais seletivas é bastante limitado nas instituições que utilizam vestibulares, particularmente as universidades públicas. 
Um exemplo ilustrativo foram os classificados no vestibular de 2006 para Jornalismo e Cinema na Universidade Federal de Santa Catarina. Não entrou nenhum estudante que tivesse cursado todo o ensino fundamental e médio público. No curso de Medicina do mesmo ano entraram somente quatro alunos do ensino médio público de um total de cem.

Do ponto de vista da renda, em 2008 (Amaral, 2008), na faixa de renda de até 3 salários mínimos estava cerca de $50 \%$ da população brasileira, porém somente $24,4 \%$ dos ingressantes nas instituições de ensino superior (IES) e 17,6\% dos concluintes. Na faixa de até 10 salários mínimos, encontravam-se $84,6 \%$ da população brasileira, 73,9\% dos ingressantes e $64,5 \%$ dos concluintes das IES. A seletividade socioeconômica não se dá somente no acesso, mas também na conclusão do ensino superior. Estes dados compreendem instituições públicas e privadas de ensino superior e não discriminam cursos, onde é conhecida a disparidade da composição do alunado do ponto de vista socioeconômico.

Do ponto de vista racial $^{1}$, a realidade é mais dura. $\mathrm{O}$ aumento vertiginoso de vagas no ensino superior brasileiro de 1960 até 1999 beneficiou quase que somente a população branca, conforme podemos ver na Figura 1 abaixo (Telles, 2003).

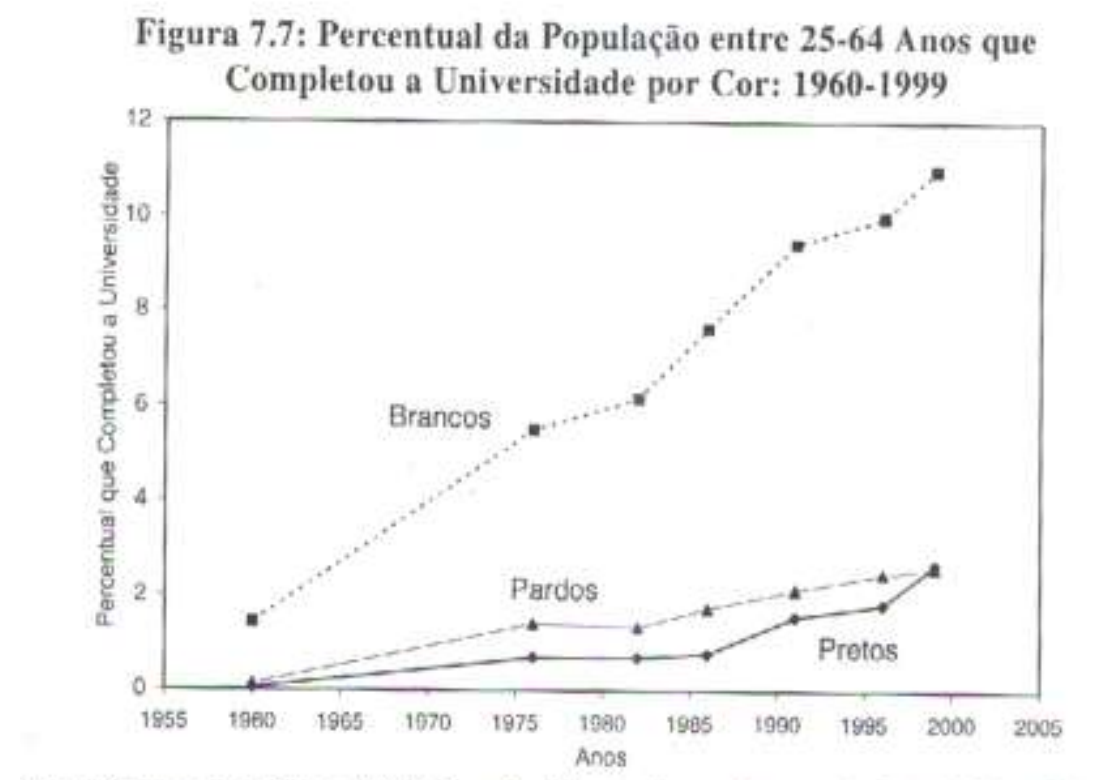

Fonte: Censos de 1960 e 1991; Pesquisa Nacional por Amostra de Domicifio - PNAD, $1976,1982,1986,1996$ e 1999.

Observação: Os pontos de dados são para 1960, 1976, 1982, 1986, 1991, 1996 e 1999.

Figura 1. Percentual da população entre 25-64 anos que completou o ensino superior por cor, de 1960 a 1999.

Observamos nesta Figura que a taxa de crescimento do percentual dos diplomados na população branca é cerca de 5 vezes maior que na população parda e preta. Esta evolução do total de diplomados fica mais dramática quando se separa em carreiras com maior e menor prestígio social, como veremos na seção 2 . Em geral, utiliza-se a classificação negra para a soma de parda e preta, dado que várias vezes estas classificações de cor/raça têm indicadores semelhantes. Esta não é uma classificação universal. O Exame Nacional do Ensino Superior (ENADE) utiliza as classificações negro e pardo, onde subentende-se que a classificação de

\footnotetext{
${ }^{1} \mathrm{O}$ conceito de raça utilizado neste artigo não se baseia na genética, mas na sua acepção social específica do Brasil, em que pessoas com fenótipos socialmente reconhecidos como negros são discriminadas.
} 
negro corresponde à de preto nas pesquisas do Instituto Brasileiro de Geográfica e Estatística - IBGE.

Nelson Cardoso Amaral (2008) mostrou que enquanto 52\% da população brasileira era branca na Pesquisa Nacional por Amostragem de Domicílios, eram brancos cerca de 73\% dos estudantes do ensino superior, enquanto que nas Instituições Federais de Ensino Superior eram 62\% (Amaral,2008).

No entanto, a partir dos dados do ENADE/2004, os negros e pardos somavam $26,9 \%$ dos ingressantes e $20,3 \%$ dos concluintes, denotando grande seletividade racial no ensino superior. Aqui foram considerados os alunos de ensino superior público e privado.

A partir de 1999 começam a ser discutidas nas universidades públicas e em algumas assembléias legislativas de estados brasileiros a adoção de políticas que compensem essas disparidades socioeconômicas e étnico-raciais.

São as chamadas políticas de ação afirmativa. Ações afirmativas

"consistem em políticas públicas (e também privadas) voltadas à concretização do princípio constitucional da igualdade material e à neutralização dos efeitos da discriminação racial, de gênero, de idade, de origem nacional e de compleição física. Impostas ou sugeridas pelo Estado, por seus entes vinculados e até mesmo por entidades puramente privadas, elas visam a combater tão somente as manifestações flagrantes de discriminação de fundo cultural, estrutural, enraizada na sociedade. "(Gomes, 2001)

Às discriminações listadas acima somaríamos a discriminação socioeconômica.

As ações afirmativas para o acesso ao ensino superior no Brasil, particularmente o ensino superior público, estão em expansão. A partir de 2002, Universidades Federais, Estaduais e Centros Universitários Municipais vêm adotando políticas de ação afirmativa para oriundos do ensino público, negros, indígenas, deficientes, entre outros segmentos sociais. Atualmente, cerca de 68\% das Universidades Federais e $65 \%$ das Universidades Estaduais têm alguma política de ação afirmativa. As modalidades mais utilizadas de ação afirmativa são reserva percentuais de vagas, bonificação na nota de ingresso e criação de vagas suplementares.

Este artigo trata do Programa de Ações Afirmativas da Universidade Federal de Santa Catarina - PAA/UFSC (UFSC, 2007), implantado a partir do vestibular para o ano de 2008. Esse programa tem várias dimensões e o objetivo deste artigo é avaliar algumas delas, particularmente no que se refere à efetividade no acesso e à permanência dos alunos de ação afirmativa. Vários dados da implantação desse Programa fornecem indicações que contrariam uma série de formulações do senso comum presentes no debate das ações afirmativas. É também objetivo deste artigo problematizar essas formulações a partir de dados concretos da experiência do PAA/UFSC.

Inicialmente, na seção 2, são descritos os fundamentos do Programa, incluindo a caracterização de profundas desigualdades econômicas e raciais, o contexto internacional, brasileiro e de Santa Catarina, do ponto de vista político, social, econômico e racial.

A seguir, é descrito na seção 3 o Programa aprovado e consubstanciado em Resolução do Conselho Universitário da UFSC, em todas as suas dimensões de preparação do acesso, acesso, permanência, banco de dados de egressos, ampliação de vagas, cursos novos e cursos noturnos.

Os primeiros dados do Programa nas dimensões preparação do acesso, acesso e permanência são expostos e analisados na seção 4.

A seção 5 traz as conclusões sobre o andamento da implantação do Programa.

2. Fundamentos e contexto de construção do PAA/UFSC 
$\mathrm{Na}$ introdução foram relatadas brevemente disparidades socioeconômicas e étnicoraciais no acesso ao ensino superior e a necessidade de ações afirmativas para corrigir essa situação. Essa correção não tem apenas justificativa social, ou seja, do ponto de vista de atenuação da desigualdade socioeconômica e étnico-racial.

Há um outro fator que é particularmente caro ao ambiente universitário de formação, que é a promoção da diversidade e da convivência de diferentes, com o objetivo de dissipar visões discriminatórias presentes nos alunos (Bowen, Bok, 2004). O momento da formação universitária é privilegiado para o conhecimento das estruturas sociais, e a convivência entre pessoas de origens socioeconômicas e étnico-raciais diferentes pode ser muito útil para a percepção de que as pessoas não são mais ou menos inteligentes, dedicadas, organizadas ou envolvidas com o curso por serem mais ou menos pobres ou por ser de cores/raças diferentes. Essa perspectiva não discriminatória vai ser levada ao mundo do trabalho. Essa pode ser uma grande contribuição da Universidade Pública no combate às discriminações socioeconômicas e étnico-raciais.

Uma vez que ações afirmativas dizem respeito a neutralizações de efeitos de discriminações, trata-se de verificar os tipos de discriminação.

É consenso no Brasil que temos uma disparidade econômica muito grande. Enquanto os $1 \%$ mais rico da população tem $13 \%$ da renda, os $50 \%$ mais pobres detêm $13,9 \%$ (IBGE, 2003). O eco no ensino superior desta desigualdade já foi citado na introdução deste artigo. Ações afirmativas de recorte socioeconômico tornam-se necessárias para garantir diversidade e acesso das pessoas de mais baixa renda ao ensino superior.

Já não é tão consensual a existência de racismo e desigualdades raciais no Brasil.

Talvez seja ilustrativo iniciar pela comparação entre a escolaridade da população negra masculina de 30-49 anos no Brasil e na África do Sul, em 1995 (Martins, 2004), representada na Figura 2.

O apartheid acabou na África do Sul em 1994, portanto estamos comparando dados de homens negros que viveram o apartheid lá com homens negros brasileiros onde não há legislação segregacionista. Observamos que o percentual de homens negros com diploma de ensino superior é próximo, enquanto que a escolarização básica (ensino fundamental e médio) dos homens negros da África do Sul é bem melhor que a dos brasileiros. A conclusão é que o Brasil, sem legislação segregacionista, obtém resultado igual (nível superior) ou pior (educação básica) do que a África do Sul!

Outro aspecto da discriminação racial no Brasil se torna evidente a partir do estudo da rede de brasileiros brancos e negros no período de 1992 a 2000 (Martins, 2004), representado na Figura 3 abaixo. 


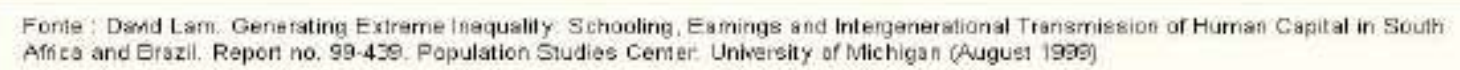

porcentagem da populaçào em cada faixa de escolaridade

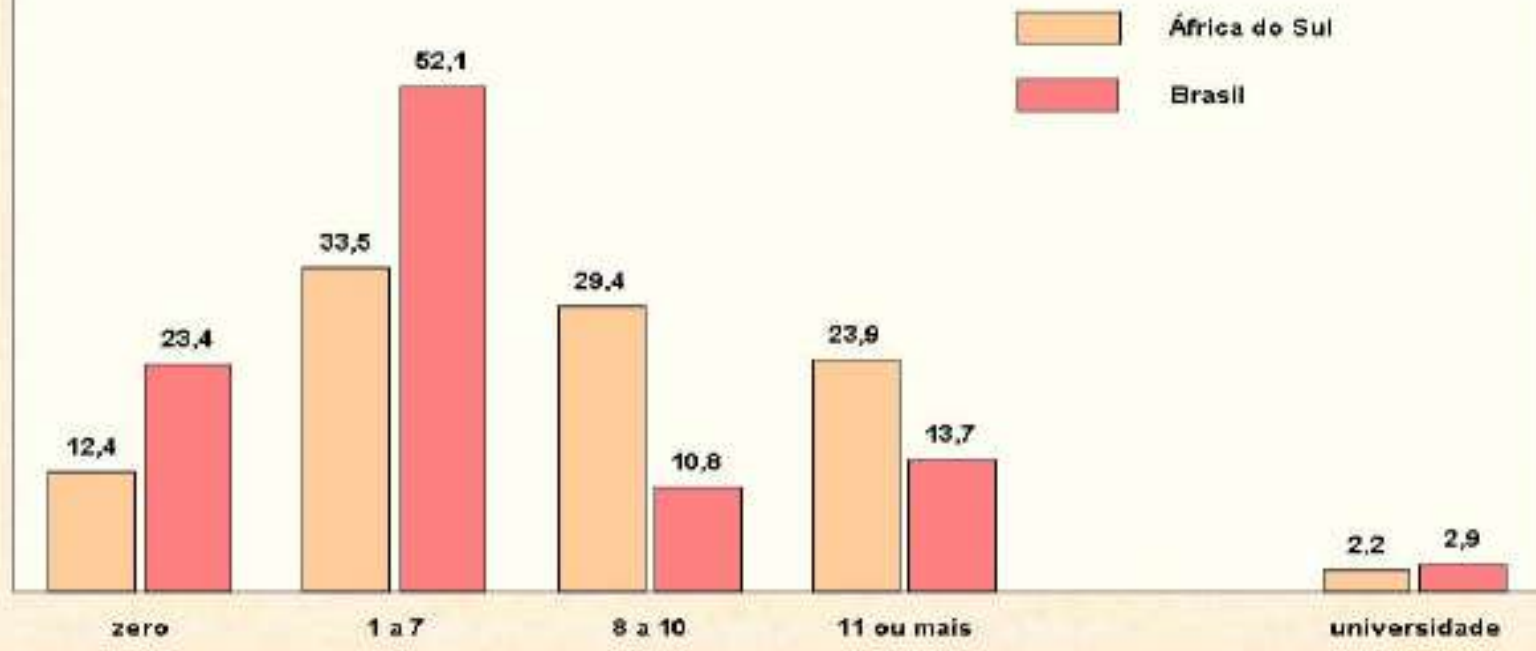

Figura 2. Escolaridade da população negra masculina (30-49 anos) em 1995 no Brasil e na África do Sul. (Martins, 2004)

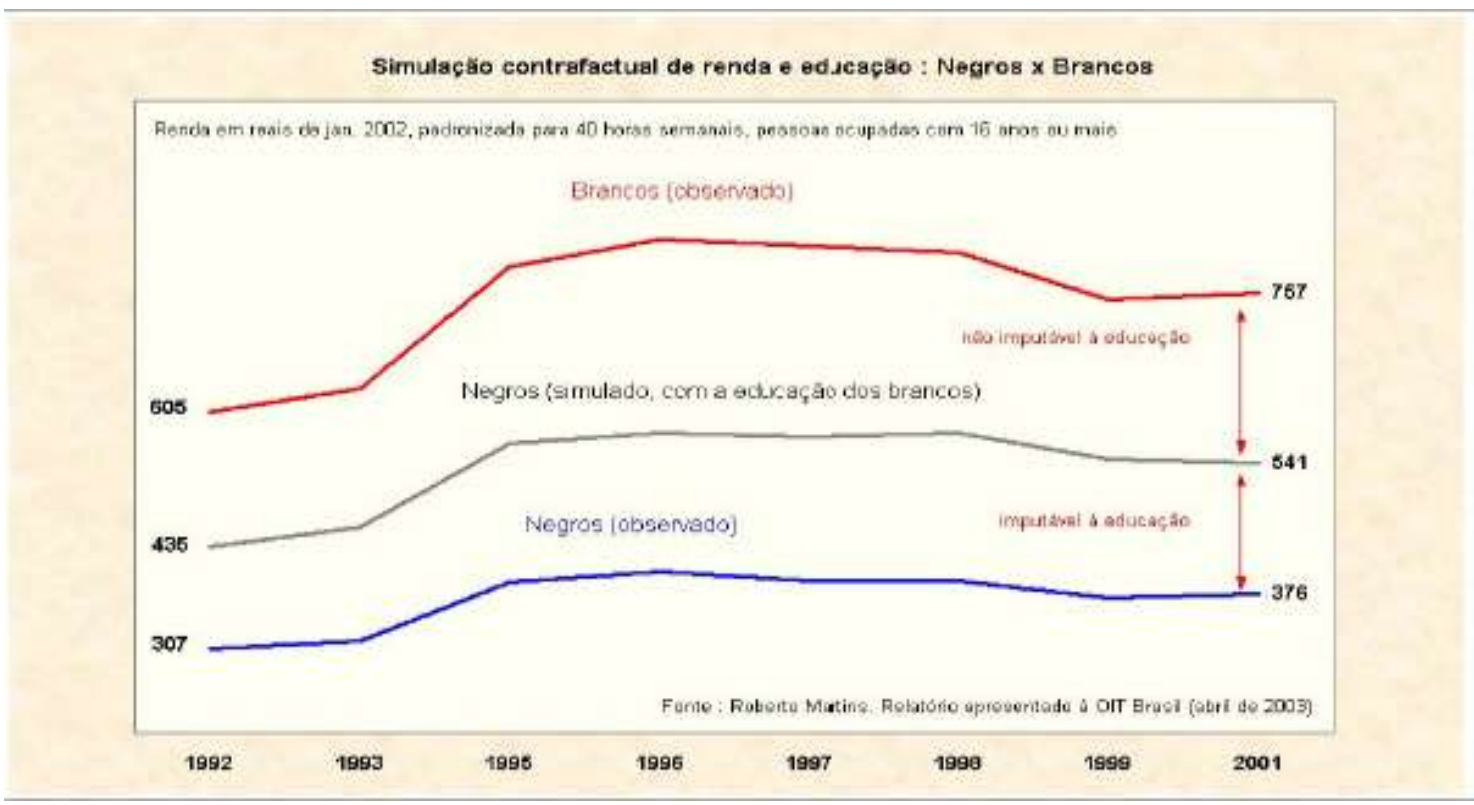

Figura 3. Renda de negros e brancos no Brasil, de 1992 a 2001. A linha vermelha representa a renda média das pessoas brancas. A linha azul representa a renda média das pessoas negras, como observado nas pesquisas. A linha cinza representa a simulação da renda média das pessoas negras com a mesma distribuição de escolaridade das pessoas brancas. (Martins, 2004)

Observa-se na Figura 3 acima que a renda média das pessoas brancas é cerca do dobro da renda média das pessoas negras, em todo o período de 1993 a 2001. No entanto, além da brutal disparidade de renda, Martins investigou se o efeito da diferença de escolaridade era determinante. Ele simulou (linha cinza da Figura 3) população negra com 
mesma distribuição de escolaridade que a branca e viu que a diferença de renda imputável à diferença de escolaridade é menor que a metade da diferença de renda entre brancos e negros. Portanto, há um efeito além do educacional. A figura sugere que, se a escolarização de negros e brancos for semelhante, haverá ainda uma grande diferença de renda. Portanto, provavelmente a renda entre brancos e negros permanecerá diferente MESMO QUE SE MELHORE O ENSINO PÚBLICO, ou seja, mesmo que a escolaridade entre negros e brancos seja semelhante. Segundo Martins (UNIFESP, 2004), isso é forte indicação de discriminação racial contra negros no mundo do trabalho.

Estudos mostram que parte do problema educacional dos negros não se dá porque são mais pobres, mas porque são negros. Telles (2003) mostrou que os irmãos negros de irmãos brancos se atrasam mais na escola, assim como as irmãs. As desigualdades raciais educacionais são visíveis dentro da mesma família.

Se focalizarmos desigualdades raciais em Santa Catarina, de onde vêm cerca de 2/3 dos candidatos ao vestibular da UFSC, veremos que o quadro não é mais alentador. $\mathrm{O}$ percentual de pretos e pardos em Santa Catarina, segundo o Censo Populacional do IBGE de 2000 era de $10,4 \%$. No entanto, o percentual de negros entre dentistas era de $0,5 \%$, entre médicos de 2,9\%, entre engenheiros de $1,7 \%$ e entre advogados de 1,5\% (Petruccelli, 2006). Note-se que todas essas profissões requerem o diploma universitário para serem exercidas, portanto a universidade tem um papel na construção da desigualdade racial em Santa Catarina.

Do ponto de vista da escolarização, Petruccelli (2004) analisou os dados de Santa Catarina no Censo Demográfico do IBGE de 2000 e verificou que $16,8 \%$ dos brancos e 9,3\% dos negros tinham o ensino médio completo, uma razão 1:1,8. Já com graduação completa havia somente $6,2 \%$ dos brancos e $1,9 \%$ dos negros, uma razão 1:3,2. Tinham mestrado ou doutorado completo $0,35 \%$ dos brancos e $0,09 \%$ dos negros, uma razão $1: 3,9$. Portanto, há uma seletividade racial crescente conforme aumenta o nível de escolaridade.

Portanto, cabe às universidades públicas de Santa Catarina uma ação contundente de forma a reverter este quadro de desigualdade racial, no seu âmbito de atuação.

Frequentemente é colocada a questão que as ações afirmativas de recorte socioeconômico, como as cotas para oriundos de escolas públicas, trariam automaticamente maior igualdade racial. Esta hipótese foi refutada, no caso do estabelecimento de cotas de $50 \%$ para oriundos de ensino médio público, para o vestibular da UFSC de 2004 (Tragtenberg et al, 2006). Naquele artigo, simula-se uma reserva de 50\% das vagas de todos os cursos da amostra, representando cursos de maior e menor prestígio social, para oriundos do ensino médio público. Verificou-se que o percentual de negros nesses cursos aumentaria de $6,8 \%$ para 7,0\%, uma diferença irrisória de 0,2 pontos percentuais. Essa política não seria capaz de aproximar significativamente dos 10,4\% de negros em SC.

Por outro lado, o contexto internacional e nacional em que estava inserida esta discussão sobre adoção de políticas de ação afirmativa de acesso ao ensino superior foi marcado por alguns eventos e projetos de lei.

A discussão das ações afirmativas no Brasil no período recente tem fundamento nas desigualdades no acesso ao ensino superior, mas teve grande impulso quanto da forte repercussão interna da participação brasileira na III Conferência Internacional sobre o Racismo, Discriminação Racial, a Xenofobia e as Intolerâncias Correlatas, ocorrida em 2001, na cidade de Durban, na África do Sul. Naquela oportunidade, a delegação brasileira defendeu cotas para negros no ensino superior, e a formulação mais geral de ação afirmativa para acesso de populações afrodescendentes à educação em todos os níveis (Declaração e Programa de Ação de Durban, 2001).

No plano nacional, está sendo discutido o Projeto de Lei Complementar 180/08 e o Projeto de Lei do Senado 344/08, que estabelecem reserva de 50\% das vagas de universidades 
federais, institutos federais de educação, ciência e tecnologia e centros federais de educação tecnológica para egressos do ensino médio ou fundamental público e, dentro dessas, uma subreserva para autodeclarados negros, pardos e indígenas, de acordo com o percentual da soma destas populações nos estados.

Além destes projetos, está em tramitação o projeto de lei 3.198/2000, denominado Estatuto da Igualdade Racial, que trouxe a discussão da inclusão do quesito cor/raça em formulários de estado, além de autorizar ações afirmativas reparatórias de desigualdades raciais em vários âmbitos, inclusive universidades federais.

Todos estes projetos de lei de âmbito nacional colocam em questão o acesso com diversidade socioeconômica e étnico-racial ao ensino superior público

\section{O Programa de Ações Afirmativas da UFSC.}

Em abril de 2006 foi constituída pelo Reitor da UFSC uma comissão com representação dos centros de ensino da UFSC, da Comissão Permanente de Vestibular da UFSC e membros da comunidade e da Secretaria de Estado da Educação de Santa Catarina. Em novembro de 2006 foi entregue ao Reitor uma proposta de Programa de Ações Afirmativas que foi apreciada pelo Conselho Universitário de maio a julho de 2007.

O Programa aprovado será descrito resumidamente neste artigo e contém os itens:

a) Preparação do acesso: divulgação do Programa, apoio à extensão em Ação Afirmativa, ampliação do Curso Pré-Vestibular gratuito da UFSC;

b) Acesso:

- reserva de 20\% das vagas de cada curso para oriundos do Ensino Fundamental e Médio público;

- reserva de $10 \%$ das vagas de cada curso para negros prioritariamente oriundos do Ensino Fundamental e Médio público;

- vagas suplementares para indígenas (5 em 2008, mais uma a cada ano);

c) Permanência: aumento da assistência estudantil (bolsas, alimentação, moradia, material didático), apoio pedagógico, formação político-social;

d) Banco de dados de egressos;

e) Aumento de vagas nos cursos;

f) Criação de cursos noturnos;

g) Constituição de comissão institucional de acompanhamento e avaliação do Programa;

h) Implantação a partir de 2008, reavaliação após cinco anos.

\section{Perguntas sobre o acompanhamento do PAA/UFSC.}

Nos limites deste artigo, abordaremos apenas os itens (a), (b) e (c) do Programa de Ações Afirmativas da UFSC.

Para tornar mais objetivo o acompanhamento do Programa, serão formuladas questões sobre seus vários aspectos:

I) A divulgação do programa foi satisfatória?

II) O Curso Pré-Vestibular foi ampliado? Ele funcionou como veículo de democratização do acesso?

III) Qual o efeito do Programa sobre o acesso à UFSC?

IV) As cotas para escola pública seriam suficientes para aumentar o acesso de negros à UFSC ou são necessárias cotas para negros? 
V) As cotas para negros devem ser restritas aos oriundos do ensino fundamental e médio público ou deve abarcar negros de outras origens escolares? VI) Como foi o rendimento dos alunos da classificação geral, das vagas reservadas para a escola pública e negros, do ponto de vista de reprovação em disciplinas?

VII) Qual foi a evasão dos alunos da classificação geral, das vagas reservadas para a escola pública e negros?

VIII) A assistência estudantil foi suficiente?

IX) $\mathrm{O}$ apoio pedagógico foi suficiente?

$\mathrm{X)}$ O suporte jurídico do Programa é consistente?

5. Metodologia

Faremos uso de diferentes metodologias para responder às várias questões.

Coletamos dados de matrículas e percentuais de aprovação do Curso Pré-Vestibular gratuito da UFSC, junto ao Curso Pré-Vestibular. Estudamos a série temporal das vagas do Curso e o percentual de aprovação nos vestibulares do ensino superior público de SC e na UFSC.

Coletamos junto à Comissão Permanente de Vestibular da UFSC dados dos classificados no vestibular desagregados pela classificação geral, escola pública e negros; os dados da classificação geral desagregados por escola pública e cor/raça; os dados de escola pública desagregados por cor/raça e os dados dos negros desagregados por tipo de origem escolar. Com base nestes dados, estudamos a série temporal do percentual de aprovados em cada modalidade de ingresso, a seletividade racial da classificação geral e das vagas reservadas para escola pública e a composição por origem escolas dos classificados pelas vagas reservadas para negros.

Coletamos junto ao sistema acadêmico de graduação da UFSC os dados de evasão e reprovação em disciplinas dos alunos da classificação geral, da reserva de vagas para a escola pública e da reserva de vagas para negros. Foram calculados os percentuais de reprovação por disciplina por centro de ensino e para o conjunto da universidade de cada modalidade de acesso. A evasão de cada modalidade de acesso foi calculada apenas para o conjunto da universidade.

$\mathrm{O}$ número de processos judiciais e de matrículas sub-judice foi levantado junto ao Departamento de Administração Escolar e à Procuradoria Jurídica da UFSC.

Os dados referentes à assistência estudantil foram coletados junto à Pró-Reitoria de Assistência Estudantil(PRAE) da UFSC, e a demanda foi confrontada com a oferta dos vários apoios.

As informações referentes à divulgação do Programa e apoio pedagógico foram coletadas junto à Comissão Institucional de Avaliação e Acompanhamento do Programa e ao Curso Pré-Vestibular da UFSC e foram avaliadas qualitativamente.

6. Resultados preliminares do PAA/UFSC.

I) A divulgação do programa foi satisfatória?

O PAA no vestibular 2008 teve divulgação em escolas da Grande Florianópolis coordenada por um membro da comissão de acompanhamento e realizada por bolsistas do Programa Conexões de Saberes em cerca de dez escolas, num programa de televisão e num jornal televisivo, além da divulgação feita pela COPERVE em algumas regionais da Secretaria de Educação. Para o vestibular 2009, o Programa teve divulgação em várias escolas por membros da comissão de acompanhamento e pela COPERVE, que também divulgou em 
algumas regionais de SC. Para o vestibular 2010, a divulgação foi bastante precária devido à epidemia da gripe suína, que fez com que se evitasse aglomerações. De forma geral, falta um planejamento para a divulgação do Programa tanto em escolas públicas, quanto em regionais da Secretaria de Educação e nos meios de comunicação de massa.

II) O Curso Pré-Vestibular foi ampliado? Ele funcionou como veículo de democratização do acesso?

O Curso Pré-Vestibular submeteu projeto de expansão e regionalização em Santa Catarina ao Ministério da Educação e foi aprovado. Um convênio entre a UFSC e a Secretaria de Estado da Educação de SC permitiu a utilização do espaço físico das escolas estaduais para a instalação do Curso Pré-Vestibular em outras cidades de Santa Catarina, além de Florianópolis. Serão atendidas vinte cidades desse estado até o fim de 2009.

$\mathrm{Na}$ Figura 4 abaixo estão representadas as pessoas atendidas pelo Curso PréVestibular, com previsão até o fim de 2009. Vemos que o atendimento aumentou de forma exponencial no período, apoiado pelo MEC e pelo convênio com a Secretaria de Estado da Educação de SC.

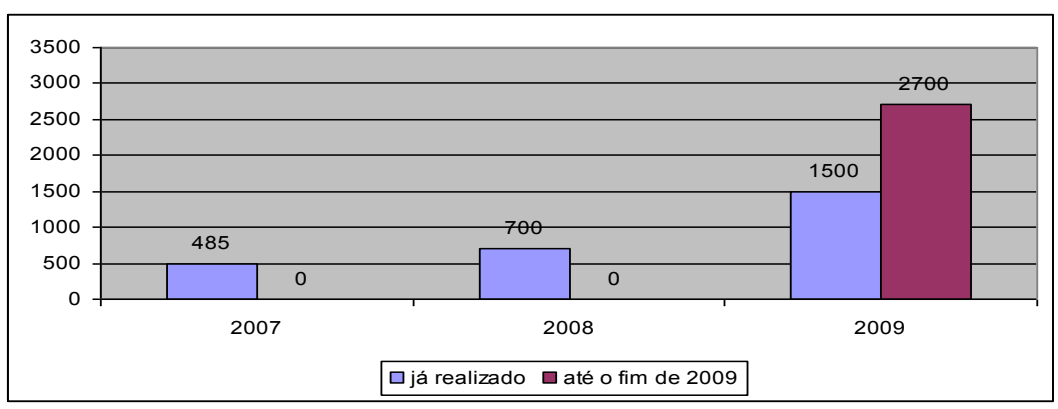

Figura 4. Pessoas atendidas pelo Curso Pré-Vestibular gratuito da UFSC nos anos de 2007 a 2009, incluindo previsão para o último ano.

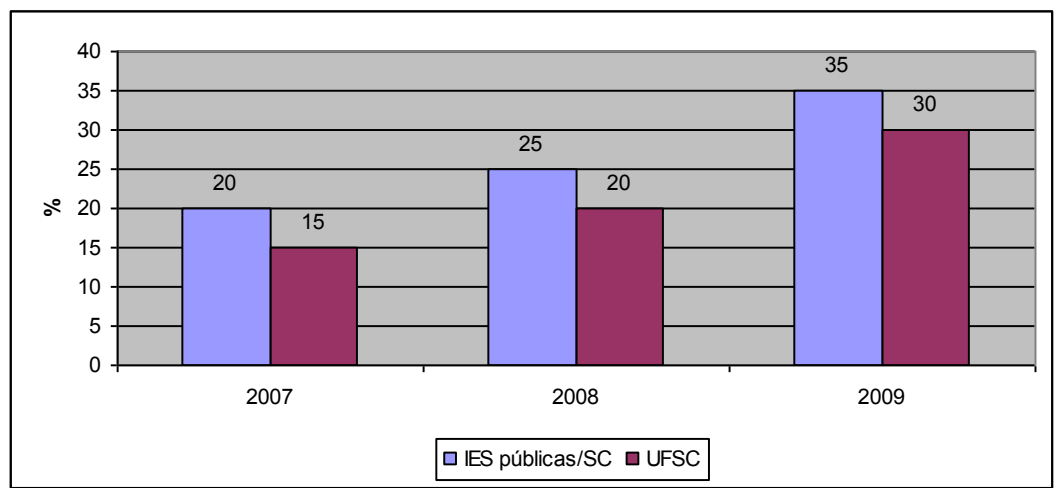

Figura 5. Percentual de aprovação dos egressos do Curso Pré-Vestibular gratuito da UFSC nas IES públicas de SC (UFSC/UDESC/CEFET) e na UFSC, nos anos 2007-2009.

Na Figura 5 acima podemos estimar a eficácia do Curso Pré-Vestibular, através do estudo do percentual de seus alunos que prestam vestibular para o ensino superior público em SC (e para a UFSC) e dos que são aprovados.

Concluímos dos dados apresentados que além da evolução quantitativa do número de pessoas atendidas, o percentual de aprovação em IES públicas de SC (UFSC, UDESC, CEFET) e na UFSC em particular vem aumentando. Os índices de aprovação em 2008 e 2009 
devem estar relacionados com a implantação do PAA. Os alunos do Curso Pré-Vestibular são todos originários do Ensino Médio Público. No entanto, esta hipótese é algo a ser investigado. Outro dado é o percentual de aprovação do Curso, acima dos cursos pré-vestibulares privados.

III) Qual o efeito do Programa sobre o acesso? Ele contribuiu para dar maior diversidade socioeconômica e étnico-racial ao corpo discente da UFSC?

Na Figura 6 abaixo estão representados os percentuais de inscritos e classificados oriundos do ensino fundamental e médio público nos vestibulares da UFSC de 2007 a 2009. Nota-se inicialmente que o percentual desses alunos no total de inscritos vem aumentando nesses anos, ou seja, esses candidatos estão se sentindo estimulados a se inscrever no vestibular da UFSC com reserva de vagas para escola pública. É muito significativo o aumento de 11,6 pontos percentuais de 2007 para 2008, o que parece refletir o impacto do Programa. No entanto, de 2008 para 2009 diminuiu o percentual desses alunos classificados. Uma razão provável é o aumento significativo de notas de corte no vestibular: as notas mínimas de Língua Portuguesa e Literatura e de Redação aumentaram de 3 para 4, num máximo de 10 pontos. A soma mínima das outras provas passou de 20 para 24 pontos sobre o máximo de 100.

Três por cento das vagas reservadas para escolas públicas não foram preenchidas em 2009 e nove cursos não tiveram suas vagas preenchidas nem pela classificação geral (Física Licenciatura, Matemática Licenciatura Diurno e Noturno, Matemática e Computação Científica, Química Licenciatura, Biblioteconomia, Serviço Social, Letras Italiano e Pedagogia). Isso deve ser provavelmente devido ao aumento dessas notas mínimas. Esse assunto deve ser investigado posteriormente. $\mathrm{O}$ aumento sucessivo das notas de corte trabalha no sentido de excluir estudantes dos cursos menos concorridos e alunos de ação afirmativas de cursos mais concorridos, que é o sentido oposto do PAA/UFSC. A instituição deve refletir qual o caminho que pretende seguir: exclusão ou inclusão.

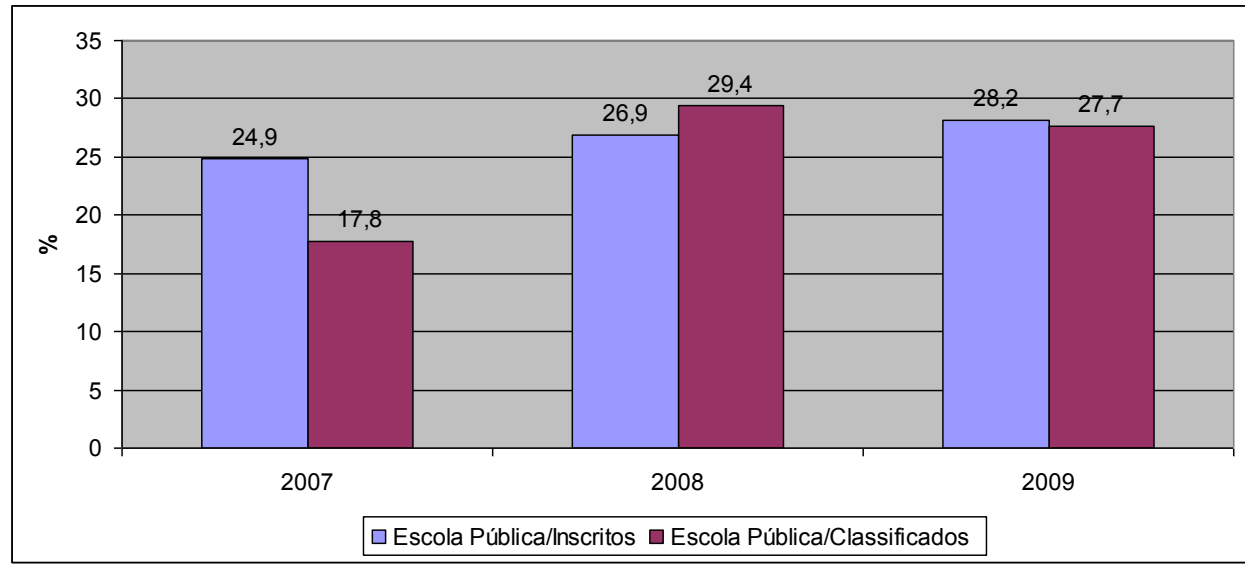

Figura 6. Percentual de egressos do ensino fundamental e médio público entre os inscritos e os classificados nos vestibulares da UFSC de 2007 a 2009.

Na Figura 7 abaixo estão representados os percentuais de negros entre os inscritos e classificados dos vestibulares da UFSC 2007-2009.

Observa-se que o percentual de negros entre os inscritos tem aumentado suavemente nesses anos, talvez pela reserva de vagas para negros. Em 2007 havia seletividade racial no vestibular (o percentual de negros inscritos era menor do que o de classificados), o que deixou de existir nos vestibulares de 2008 e 2009, com o PAA. O aumento do percentual de classificados negros de 2007 a 2008 foi formidável. No entanto, este percentual teve queda 
significativa em 2009, provavelmente devido ao aumento de notas mínimas em várias provas. Em 2008, somente $75 \%$ das vagas reservadas para negros foram preenchidas. Já em 2009, apenas $60 \%$ delas foram preenchidas. Em 2008, cerca de 550 pessoas autodeclaradas pretas e pardas optaram pela reserva de vagas para negros. Este número que aumentou para cerca de 1000 pessoas em 2009, aumento de $82 \%$ nas inscrições. No entanto, ingressaram 329 alunos em 2008 (total de 4200 vagas) e 279 em 2009 (total de 4500 vagas). Novamente, esse decréscimo deve ter sido efeito do aumento das notas mínimas.

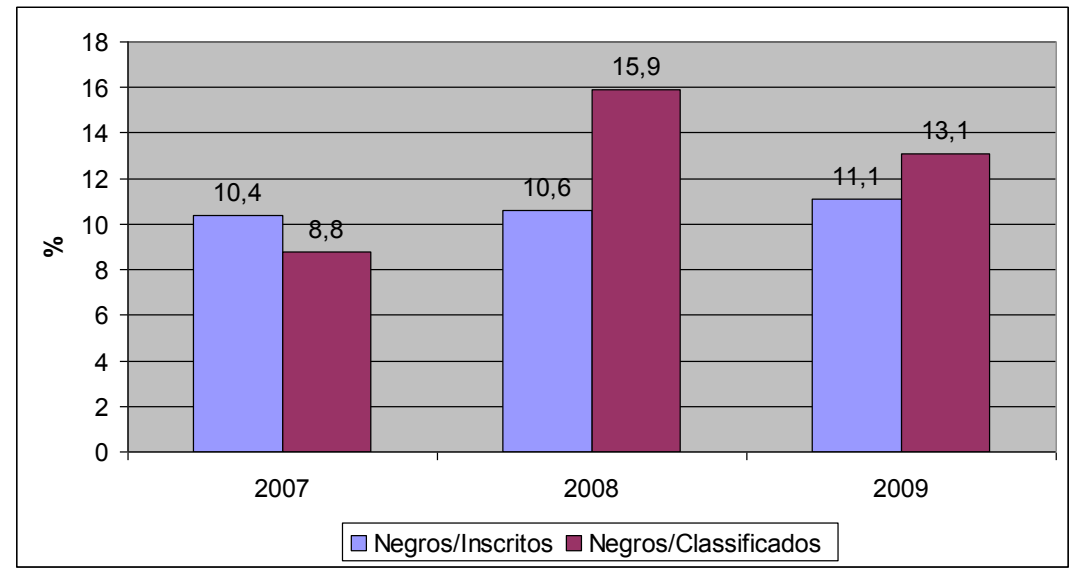

Figura 7. Percentual de autodeclarados negros (da classificação geral, optantes pela reserva para escola pública e pela reserva para negros) entre os inscritos e entre os classificados dos vestibulares 2007-2009.

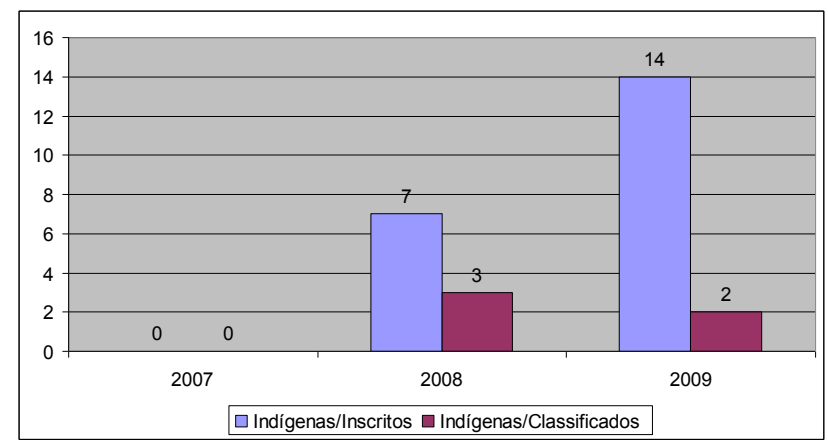

Figura 8. Número de candidatos indígenas inscritos e classificados nos vestibulares de 20072009.

Na Figura 8 acima estão representados os candidatos e classificados indígenas. Só entram indígenas na UFSC pelo PAA. Notamos que as vagas suplementares para indígenas não foram preenchidas em 2008. Eram cinco dessas vagas, três indígenas se classificaram e dois se matricularam. Já em 2009, com seis vagas reservadas, dobrou o número de candidatos, mas só dois indígenas passaram e um não teve sua autodeclaração validada. No total entraram em 2008 e 2009 somente três indígenas. O aumento da nota de corte ligada ao Português contribuiu para a exclusão dos indígenas. Se as notas de corte fossem as de 2008 e os indígenas pudessem zerar na soma das questões discursivas, mais quatro indígenas teriam ingressado na UFSC em 2008 e 2009.

IV) As cotas para escola pública seriam suficientes para aumentar o acesso de negros à UFSC ou são necessárias cotas para negros? 
Nota-se na Figura 9 abaixo que há seletividade racial leve na classificação geral e escola pública em 2008, que se acentua em 2009. Mas em 2009 a seletividade de escola pública foi mais acentuada, ao contrário do que o senso comum poderia supor. Observa-se que a pequena diferença entre negros aprovados pela classificação geral e pelas vagas reservadas para escola pública permite concluir que se houvesse somente reserva de vagas para escola pública o percentual de negros estaria bem abaixo dos 13\% em 2009. Ele estaria em torno de 7,5\%, de forma geral, sem levar em consideração os classificados por curso. Portanto, as cotas para escola pública são insuficientes para garantir um ingresso significativo de negros na UFSC. Cotas para negros são necessárias.

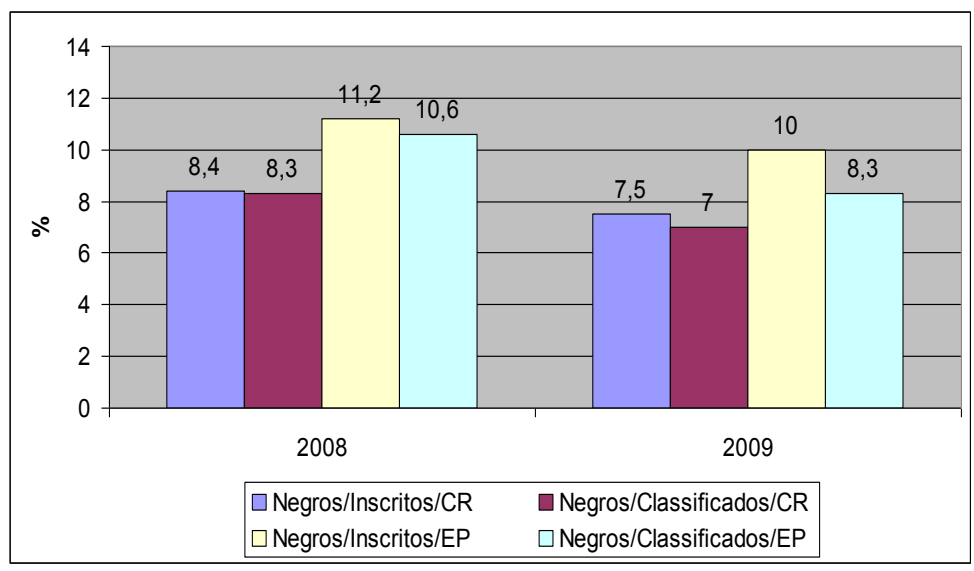

Figura 9. Percentual de negros inscritos e classificados na classificação geral e optantes pelas vagas reservadas para escolas públicas nos vestibulares de 2008 e 2009 . Houve redução significativa provavelmente devido ao aumento das notas de corte de 2008 para 2009.

V) As cotas para negros devem ser restritas aos oriundos do ensino fundamental e médio público ou deve abarcar negros de outras origens escolares?

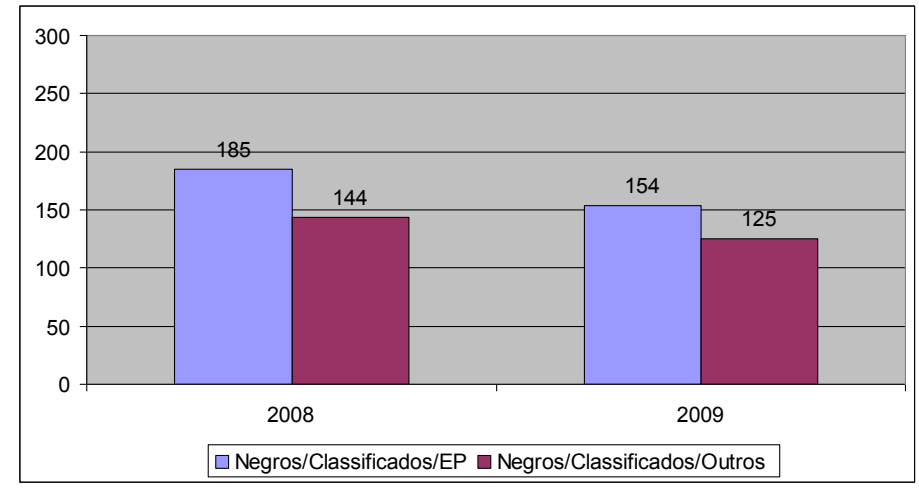

Figura 10. Números de optantes pelas vagas reservadas para negros de educação básica pública ou de outro percurso escolar, classificados nos vestibulares de 2008 e 2009.

O percentual de classificados que ingressaram pelas vagas reservadas para negros nos vestibulares de 2008 e 2009 que eram egressos de escola pública eram cerca de $55 \%$ dos optantes pelas cotas para negros, conforme a figura 10 acima. Logo, para que houvesse ingresso significativo de negros, foi necessário que negros que não fizeram a educação básica em escola pública pudessem concorrer às vagas reservadas para negros. Há grande seleção de negros na educação básica pública ou privada, daí o pequeno número de negros classificados no vestibular. A prioridade para negros egressos de escolas públicas na reserva de vagas para 
negros garante maior diversidade socioeconômica nessa reserva, provavelmente. Este tópico também deve ser objeto de pesquisa posterior.

VI) Como foi o rendimento dos alunos da classificação geral, das vagas reservadas para a escola pública e negros, do ponto de vista de reprovação em disciplinas?

De forma geral, 18,8\% das matrículas dos calouros de 2008.1 da classificação geral resultaram em reprovação. Para os alunos da reserva de vagas para escola pública o percentual foi de $19,4 \%$ e para os da reserva para negros foi $27,7 \%$. Nota-se que a diferença é mínima entre a classificação geral e os de escola pública, sendo os negros mais reprovados.

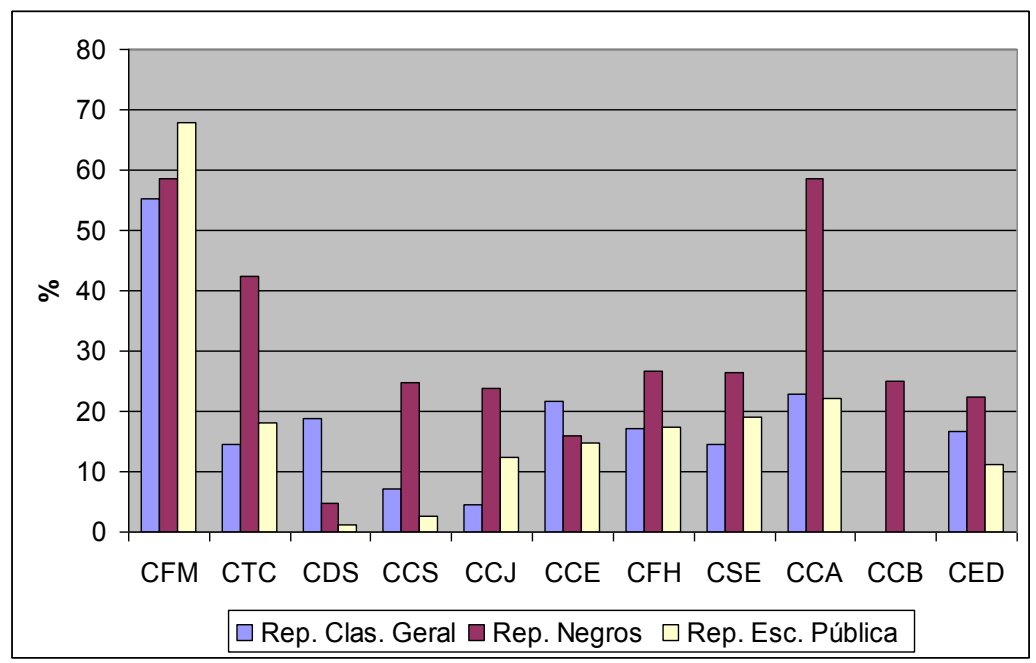

Figura 11. Percentual de reprovação em disciplinas em 2008.1 dos calouros da classificação geral, da reserva para escolas públicas e para negros, por centro de ensino da UFSC.

Notamos que a reprovação é grande e relativamente indiferenciada no Centro de Ciências Físicas e Matemáticas e muito grande para negros no Centro de Ciências Agrárias e no Centro Tecnológico, conforme a Figura 11. Os negros têm menos reprovação no Centro de Desportos e no Centro de Comunicação e Expressão. Nos outros centros, em geral a reprovação da escola pública é próxima à da classificação geral, já no primeiro semestre.

O senso comum que o aluno de escola pública é mais reprovado que o da classificação geral não se sustenta, ao menos em 2008.1.

VII) Qual foi a evasão dos alunos da classificação geral, das vagas reservadas para a escola pública e negros?

O percentual de alunos evadidos em 2008 na classificação geral foi de 9,0\%, na reserva de vagas para escola pública foi de 5,5\% e na reserva de vagas para negros foi de $4,2 \%$. Portanto, a evasão dos alunos de ação afirmativa foi bem menor que os da classificação geral, sendo a dos negros menor. Eles, mesmo mais reprovados, permanecem mais na universidade. É gente acostumada às adversidades da vida, são guerreiros e guerreiras.

VIII) A assistência estudantil foi suficiente?

As bolsas de manutenção (bolsas permanência) de 360 reais/mês, segundo dados fornecidos pela Pró-Reitoria de Assistência Estudantil, foram suficientes em 2008.1, 2008.2 e 2009.1. Em 2008.1 94 alunos de ação afirmativa se inscreveram e 93 foram selecionados. Em 
2008.2 155 se inscreveram e foram selecionados. Em 2009.150 se inscreveram e 50 foram selecionados.

Com relação ao auxílio-moradia, no valor de 200 reais mensais, 4 meses por semestre, houve insuficiência de atendimento em 2009, conforme a tabela 1 abaixo. Isso mostra necessidade de maior alocação de recursos nesta área.

\begin{tabular}{|l|c|c|c|}
\hline PERÍODO & INSCRITOS & SELECIONADOS & $\begin{array}{l}\text { NÃO } \\
\text { ATENDIDOS }\end{array}$ \\
\hline 2008.1 & 45 & 45 & 0 \\
\hline 2008.2 & 88 & 88 & 0 \\
\hline 2009.1 & 140 & 59 & 81 \\
\hline 2009.2 & 262 & 186 & 76 \\
\hline
\end{tabular}

Tabela 1. Alunos de ações afirmativas inscritos, selecionados e não atendidos nos pedidos de auxílio-moradia em 2008.1, 2008.2, 2009.1 e 2009.2.

A Pró-Reitoria de Assistência Estudantil (PRAE) dá bolsa nos cursos de língua estrangeira extra-curriculares, oferecidos pelo Centro de Comunicação e Expressão da UFSC. A tabela 2 resume os dados, mostrado crescimento de demanda de 2008 para 2009 e insuficiência de bolsas para estudantes de ação afirmativa realizarem esses estudos.

\begin{tabular}{|l|l|l|l|}
\hline PERÍODO & INSCRITOS & SELECIONADOS & $\begin{array}{l}\text { NÃO } \\
\text { ATENDIDOS }\end{array}$ \\
\hline 2008.1 & 45 & 45 & 0 \\
\hline 2008.2 & 88 & 88 & 0 \\
\hline 2009.1 & 140 & 59 & 81 \\
\hline 2009.2 & 262 & 186 & 76 \\
\hline
\end{tabular}

Tabela 2. Alunos de ação afirmativa inscritos, selecionados e não atendidos na solicitação de bolsa nos cursos de língua estrangeira extra-curriculares.

No momento em que este artigo está sendo redigido faltam os dados de isenção do restaurante universitário da UFSC para alunos de ação afirmativa.

A PRAE comprou um conjunto de cerca de doze kits para os alunos de baixa renda do curso de odontologia, que serão a eles emprestados e por ele devolvidos na conclusão do curso. A insuficiência de recursos dos alunos de Arquitetura na feitura de maquetes, que são pagas no caso dos alunos da classificação geral, ainda não havia sido equacionado até o momento da redação deste artigo.

IX) O apoio pedagógico foi suficiente?

Em 2008, houve duas experiências piloto de um mês em cada semestre de apoio pedagógico nas disciplinas de física, química, matemática, redação/interpretação de texto, organizadas pelo Curso Pré-Vestibular da UFSC. Em 2009 foi organizado um curso de inverno com oitenta inscritos, nas matérias de matemática, física, química, redação/interpretação de texto e inglês. Dois cursos de pós-graduação, Automação e Física, alocaram alunos para apoio à graduação em 2009, sendo que Automação já havia feito isso em 2008. 
Há uma iniciativa institucional de estimular os bolsistas REUNI de pós-graduação de assistência ao ensino para apoiar áreas críticas da graduação como física, matemática, química, computação, bioquímica, redação/interpretação, inglês. A iniciativa ainda não se encontra devidamente estruturada.

X) O suporte jurídico do Programa é consistente?

Em 2008 houve 88 processos contra o PAA/UFSC, sendo que no presente momento ainda um ingressante em 2008.1 se encontra matriculado e 14 ingressantes em 2008.2 estão na mesma situação.

Em 2009 o número de processos contra o PAA/UFSC foi de 121, sendo que 4 ingressantes de 2009.1 e 44 de 2009.2 se encontram matriculados.

\begin{tabular}{|l|l|l|}
\hline & Processos & Ainda matriculados \\
\hline 2008 & 88 & $1(2008.1)+14(2008.2)$ \\
\hline 2009 & 121 & $4(2009.1)+44(2009.2)$ \\
\hline
\end{tabular}

Tabela 3. Número de processos contra o PAA/UFSC em 2008 e 2009 e número de alunos ainda matriculados ingressantes em 2008.1,2 e 2009.1,2.

Dada a morosidade judicial, alguns alunos de 2008 que ingressaram por processo judicial ainda encontram-se matriculados, sendo maior o número de alunos de 2009.2 pois não houve tempo de questionamento das liminares que garantem suas matrículas.

Como é pequeno o número de alunos que conseguem se matricular (ainda nenhum processo destes foi transitado em julgado), podemos assegurar que este programa tem consistência jurídica, até o momento. Está em julgamento no Supremo Tribunal Federal (STF) uma ação contra o PROUNI que envolve o questionamento das cotas daquele programa. A decisão do STF certamente terá repercussão no PAA/UFSC, seja pela legitimação, seja pelo questionamento.

\section{Conclusões.}

Os dados discutidos na seção 6 indicam a justeza e conveniência da UFSC adotar reservas de vagas para escolas públicas, negros e indígenas.

$\mathrm{O}$ acesso foi mais democrático, seja pela ampliação de estudantes de escolas públicas em todos os cursos, bem como de negros e o ingresso de indígenas. Mais estudantes desses segmentos estão sendo estimulados a se inscrever e optar pelas vagas para cada segmento, no curto período de avaliação.

$\mathrm{O}$ estabelecimento de reservas de vagas para negros independentemente da reserva para egressos de escola pública foi essencial ao aumento substancial de negros na UFSC.

A definição dessa reserva priorizando os estudantes negros de educação básica pública, mas não excluindo os negros com outro percurso escolar se justifica pelo baixo percentual de negros de escola pública que conseguem se classificar no vestibular. Vários dos negros de outro percurso escolar foram bolsistas em escolas privadas ou fizeram supletivo.

$\mathrm{O}$ aproveitamento dos cotistas de escola pública mostrou-se semelhante aos estudantes da classificação geral. $\mathrm{O}$ aproveitamento dos negros foi menor, porém este segmento é o de menor evasão. A evasão dos alunos de ação afirmativa de escola pública também é menor que a da classificação geral. O número de alunos evadidos da classificação geral é próximo ao de vagas reservadas para negros. 
A demanda por assistência estudantil é crescente e exige maior investimento da UFSC. O Programa tem consistência jurídica, tendo poucos processos garantido matrícula a seus impetrantes.

\section{REFERÊNCIAS BIBLIOGRÁFICAS}

AMARAL, N. C. O REUNI, o acesso e a permanência na Educação Superior. In: SEMINÁRIO DE ACESSO AO ENSINO SUPERIOR, 2008, Rio Quente/Goiás, Influência do REUNI nas condições de acesso ao ensino superior das universidades públicas. Disponível em: <http://www.vestibular.ufg.br/saes/programacao.html>. Acesso em: 15 set. 2009.

BOWEN, W.; BOK, D. O Curso do Rio. Rio de Janeiro: Editora Garamond, 2004.

GOMES, J. B. B. Ação Afirmativa \& Princípio Constitucional da Igualdade: o direito como instrumento de transformação social. A experiência dos EUA. Rio de Janeiro: Renovar, 2001.

Declaração e Programa de Ação da III Conferência contra o Racismo, a Discriminação Racial, a Xenofobia e Intolerâncias Correlatas de Durban. Disponível em: $<$ http://www.lpp-uerj.net/olped/documentos/1693.pdf>. Acessado em 15 set. 2009.

INSTITUTO BRASILEIRO DE GEOGRAFIA E ESTATÍSTICA Estatísticas do Século XX. Rio de Janeiro, 2003. Disponível em: <http://www.ibge.gov.br/seculoxx/default.shtm>. Acessado em 15 set. 2009.

Martins, R. B. Desigualdades Raciais e Ações Afirmativas no Brasil, Palestra apresentada em reunião do Conselho Universitário da Universidade Federal de São Paulo, 10 mar. 2004, arquivo em pdf.

PETRUCCELLI, J. L. Mapa da cor no ensino superior brasileiro. Rio de Janeiro: Programa Políticas da Cor na Educação Brasileira/UERJ, 2004. Disponível em: $<$ http://www.lpp-uerj.net/olped/documentos/ppcor/0301.pdf>. Acessado em 15 set. 2009.

PETRUCCELLI, J. L. Comunicação pessoal realizada em 2006 baseada em levantamento deste pesquisador do IBGE junto ao Censo Populacional do IBGE de 2000.

TELLES, E. Racismo à brasileira: uma nova perspectiva sociológica. Rio de Janeiro: Relume Dumará, 2003.

TRAGTENBERG, M. H. R. et al. Como aumentar a proporção de estudantes negros na universidade? Cadernos de Pesquisa, São Paulo, v. 36, n. 128, p.473-395, maio/ago 2006.

UFSC - UNIVERSIDADE FEDERAL DE SANTA CATARINA - Resolução 08/CUN/2007,

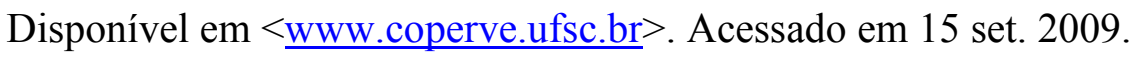

UNIFESP - UNIVERSIDADE FEDERAL DE SÃO PAULO, Ata de reunião do Conselho Universitário de 10 de março de 2004. Disponível em: $<$ http://www.unifesp.br/reitoria/orgaos/conselhos/consu/atas/100304.htm>. Acesso em 15 set. 2009. 